Grażyna Ryba

Uniwersytet Rzeszowski

\title{
Święci z kościoła w Krasnem koło Rzeszowa. Przyczynek do badań nad twórczością Stefana Matejki
}

W podrzeszowskiej parafii Krasne, obchodzącej jubileusz 600-lecia istnienia znajduje się zabytkowy kościół pw. Wniebowzięcia Najświętszej Marii Panny wzniesiony w latach 1742-1752 w stylu prowincjonalnego późnego baroku (il. 1). Wnętrze tej niewielkiej świątyni zdobi interesujący witraż, który można łączyć z działalnością Stefana Matejki oraz związane z nim formalnie malowidło ścienne ${ }^{1}$.

Jednoprzestrzenna budowla składa się z prostokątnej nawy i nieco węższego prezbiterium, zakończonego wieloboczną apsydą. W ścianach nawy umieszczono duże, wydłużone okna zamknięte półkoliście. Wnęki okienne o podobnym kształcie znajdują się w ścianach prezbiterium i apsydy. Są one jednak zamurowane, z wyjątkiem jednego okna w ścianie południowej prezbiterium. Wypełnia je wspomniany witraż, zawierający przedstawienie o charakterze figuralnym. $\mathrm{Na}$ przeciwległej ścianie w zamurowanej wnęce okiennej znajduje się malowidło, ukazujące postaci i sceny w analogicznym ujęciu kompozycyjnym. Natomiast w oknach nawy, rozmieszczonych regularnie po cztery w ścianie północnej i południowej wprawiono witraże o formach geometrycznych.

\footnotetext{
${ }^{1}$ Autorka pragnie złożyć podziękowania Danucie Czapczyńskiej-Kleszczyńskiej za cenne uwagi na temat sztuki witrażu na przełomie XIX i XX wieku i udostępnienie materiałów z jej bogatego zbioru archiwaliów. W bibliografii prac tej badaczki istotne miejsce zajmują publikacje poświęcone krakowskim pracowniom witrażu, a więc także ich realizacjom na terenach Polski południowo-wschodniej. Z badaniami nad sztuką witrażową na Podkarpaciu na przełomie XIX i XX wieku wiążą są też teksty Andrzeja Laskowskiego, omówione w artykule Danuty Czapczyńskiej-Kleszczyńskiej, Zapomniani twórcy, stan badań nad polskim witrażownictwem (druga połowa IXI w. - rok 1945), „Sacrum et Decorum. Materiały i studia z historii sztuki sakralnej" 1 (2008), s. 94-103.
} 
Kolejne wizytacje biskupie od połowy XVIII wieku wymieniały w kościele „11 okien wielkich w ołów oprawnych” $(1755,1792)^{2}$. Zapewne chodziło o pięć okien w prezbiterium, cztery - w nawie i pozostałe może w elewacji frontowej. W XIX wieku kolejne protokoły posiedzeń rady parafialnej zawierały informacje dotyczące zakupu szyb bądź naprawy okien, jak na przykład w 1886 roku, gdy wydano proboszczowi ,pełnomocnictwo, by naprawił rysy w oknach”3. W 1889 roku postanowiono „wyrwać dwa okna i zasklepić, a przez wszystkie cztery okna dać żelazne ankry, a inne okna wyklinować"4. Można przypuszczać, że zdecydowano się ,zasklepić”, czyli zamurować dwa okna w prezbiterium i że zapewne postanowienie to wykonano. W 1892 roku ponownie zalecono ,wzmocnienie okien" ". Widocznie następujące po sobie reparacje niewiele pomogły, bo w lipcu 1893 roku postanowiono „zrobić wszystkie nowe okna”. Realizacja tego postanowienia odwlekała się do 1901 roku, kiedy to zdecydowano się „zamurować dwa okna przy wielkim ołtarzu, a pięć okien w kościele zamówić w ramach żelaznych i ołowianych we Wiedniu (Geyling)"”?

Wspomniany zakład Geylinga była to znana w całej Europie firma witrażownicza założona w 1840 roku we Wiedniu ${ }^{8}$. Same ramy można było zamówić gdzie indziej - bliżej, mniejszym kosztem. Skoro zamierzono udać się aż do Wiednia, prawdopodobnie miały to być nie tylko zwykłe okna w ramach, ale cztery witraże w nawie i piąty - jedyny w prezbiterium, po zamurowaniu w 1901 roku dwu kolejnych okien. Należy podkreślić, że wiedeńska pracownia Geylinga była znana w okolicach Rzeszowa i rywalizowała z powodzeniem z krakowskim zakładem Teodora Zajdzikowskiego, który mniej więcej w tym samym czasie realizował zamówienie na podobne, geometryczne przeszklenia do kościoła w nieodległej Mrowli. Z pracowni Geylinga pochodzą witraże między innymi w pobliskich obiektach sakralnych: Albigowej, Łańcuta, Cieklina czy Sękowej (obecnie nieistniejące).

${ }^{2}$ Odpisy wizytacji w: Archiwum Urzędu Parafialnego w Krasnem, Ks. J. Rąb, Dzieje Krasnego, 1965, mps, brak numeracji stron.

${ }^{3}$ Archiwum Urzędu Parafialnego w Krasnem, Protokół Czynności Komitetu Parafialnego w Krasnem 1886, rkps, brak numeracji stron.

${ }^{4}$ Archiwum Urzędu Parafialnego w Krasnem, Protokót Czynności Komitetu Parafialnego w Krasnem 1887-1946, rkps, brak numeracji stron.

${ }^{5}$ Tamże.

${ }^{6}$ Tamże.

${ }^{7}$ Tamże.

${ }^{8}$ Por. J. Oršulová, Sklomaliarska Firma Karola Geylinga, „Zborník Slovenského Národného Múzea" 92 (1998), s. 5-24; A. Laskowski, Über die Arbeiten der Wiener Glasmalereiwerkstatt Carl Geyling 's Erben in Galizien, „Jahrbuch des Wissenschaftlichen Zentrums der Polnischen Akademie der wissenschaften in Wien" Bd. 2 (2009), s. 12-142.

${ }^{9}$ Por. D. Czapczyńska, Teodor Andrzej Zajdzikowski (1840-1907), pionier krakowskich witrażowników, „Rocznik Krakowski” LXIX (2003), s. 163. 
W Krasnem jednak zrezygnowano ze współpracy z wiedeńską firmą, gdyż późniejsze dokumenty parafialne już o niej nie wspominają, natomiast w dzienniku podawczym pod datą 26 kwietnia 1903 roku znajduje się notatka: „wysłano 200 koron za okna do kościoła prof. Ekielskiemu, pierwsza rata kwartalna". Zadatkowane w kwietniu przeszklenia już w lipcu zostały wstawione do kościoła, gdyż 23 tego miesiąca zostało zapisane, że „wręczono p. Tuchowi na miejscu przy osadzaniu okien 200 koron”. Poniżej znajduje się własnoręczny podpis Antoniego Tucha. Kolejne raty wysyłano co kwartał ,prof. Ekielskiemu i Tuchowi w Krakowie" po 200 koron: 2 stycznia, 1 kwietnia, 1 lipca i 7 października 1904 roku, a następnie: 2 stycznia, 31 marca i 16 lipca 1905 roku. Z początkiem roku 1906 proboszcz ks. Stanisław Siara przesłał do Krakowa 300 koron i z wyraźną ulgą zanotował: „winienem jeszcze tylko 100 koron” ${ }^{10}$. W sumie więc kraśnieńskie okna kosztowały 2400 koron spłacanych ratami w latach 1903-1906 ${ }^{11}$.

Były to cztery okna w nawie z prostymi podziałami geometrycznych tafli szkła katedralnego o właściwej sobie nierównej fakturze, które tworzyły rytmiczne układy w trzech zaledwie barwach: zielonej i żółtej z drobnymi punktami czerwieni. Natomiast w jedynym zachowanym oknie prezbiterium umieszczono witraż figuralny według projektu Stefana Matejki ${ }^{12}$. O tym właśnie witrażu pisze Ekielski w liście do nieznanego duchownego (list zachowany w kopiale) w lipcu 1904 roku: „Przewielebny Księże Dziekanie Dobrodzieju, pod naszą nieobecność łaskaw był Przewielebny Ksiądz Dziekan odwiedzić nasz zakład. Nieznany jest nam bliżej cel jego łaskawej u nas wizyty [...], w każdym razie bylibyśmy bardzo chętnie pokazali Przewielebnemu Księdzu Dziekanowi Dobrodziejowi nasz zakład, który dzięki Bogu rozwija się pomyślnie. Mimo że istniejemy niewiele więcej jak dwa lata możemy wykazać się szeregiem pokaźnych prac [...]"13. W załączonym wykazie realizacji obejmującym około dwudziestu pozycji Ekielski wymienia na

${ }^{10}$ Archiwum Urzędu Parafialnego w Krasnem, Protokót Czynności Urzędowych Parafii w Krasnem 1897-1937, rkps, brak numeracji stron.

${ }^{11}$ Potwierdzenie informacji zawartych $\mathrm{w}$ archiwum parafialnym znajduje się w materiałach zgromadzonych przez niestrudzoną badaczkę sztuki witrażu p. Danutę Czapczyńską-Kleszczyńską, która jest w posiadaniu odpisu listu W. Ekielskiego zawierającego spis realizacji jego zakładu. Tam między innymi wymieniono Krasne. W bilansie firmy wśród dłużników w latach 1902-1905 także wymieniono proboszcza Krasnego, ks. Siarę. Por. Archiwum S. G. Żeleński, Bilans za lata 1902-1905 firmy Krakowski Zakład Witrażów wytrawiania na szkle i oszkleń artystycznych Prof. Władysława Ekielskiego i Antoniego Tucha, odpis w posiadaniu p. Danuty Czapczyńskiej-Kleszczyńskiej.

${ }^{12} \mathrm{O}$ tym, że jest to dzieło Stefana Matejki, informuje tylko notatka sporządzona w zakładzie Żeleńskich podczas konserwacji: Krasne 1959 repar. Matejki Stef. (Wykaz robót witrażowych od 1929 roku, oprac. Adam Żeleński, informacja uzyskana dzięki uprzejmości p. Danuty CzapczyńskiejKleszczyńskiej, dysponującej odpisem dokumentu).

${ }^{13}$ Archiwum S. G. Żeleński, Bilans za lata 1902-1905 firmy Krakowski Zakład Witrażów..., dz. cyt. 
trzeciej pozycji: „witraż barokowy w kościele parafialnym w Krasnem”, a tuż za nim „dwa witraże w kościele parafialnym w Staromieściu pod Rzeszowem” ${ }^{14}$.

Widocznie prace wykonane przez krakowski zakład w kościele w Krasnem były skutecznie i dobrze przeprowadzone, ponieważ przez następnych dwadzieścia lat pomija się milczeniem kwestie konserwacji okien. Dopiero w roku 1922 „postanowiono z dobrowolnych składek naprawić okna w kościele”15; podobne postanowienie zawiera też sprawozdanie Komitetu Parafialnego z 1928 roku $^{16}$.

Kolejne prace związane z oknami podjęto podczas rozbudowy kościoła, która nastąpiła w latach 1935-1936. Wydłużono nawę i dodano po dwa okna w ścianie północnej i południowej. Po powiększeniu kościoła w 1936 roku zakład Żeleńskich dokonał remontu pięciu istniejących okien witrażowych o powierzchni łącznej 35 $\mathrm{m}^{2}$ (zapewne czterech w nawie i jednego w prezbiterium). W dobudowanej części wstawiono cztery witraże geometryczne o powierzchni $28,20 \mathrm{~m}^{2}$ powielające wzór, występujący na tych, które wykonano wcześniej w zakładzie należącym jeszcze do Ekielskiego i Tucha ${ }^{17}$. Nowe okna można odróżnić po nieco jaśniejszym odcieniu zastosowanych barw. Są też na nich inskrypcje, zawierające nazwiska fundatorów oraz nazwę zakładu i datę wykonania prac ${ }^{18}$. Wkrótce potem, ale zapewne już po 1938 roku, w prezbiterium, w zamurowanej wnęce naprzeciw istniejącego przeszklenia wykonano jego odpowiednik - malowidło, które zachowywało układ kompozycyjny witrażu i zawierało sceny figuralne. Stanowiło ono swoistą iluzję okna witrażowego.

Później podejmowano już tylko prace konserwatorskie. W 1946 roku ,poprawę okien witrażowych uchwalono oddać Zygmuntowi Świrgoniowi”"19, miejscowemu rzemieślnikowi. Gruntownej reparacji witraża Stefana Matejki dokonał Zakład Żeleńskich w roku $1959^{20}$.

Jest to niewątpliwie najbardziej interesujące dzieło w zespole przeszkleń barokowego kościoła w Krasnem (il. 2). Ozdobne barokowo-rokokowe obramienie dzieli okno na trzy sceny ujmujące: sylwetkę gołębicy Ducha Świętego w górze, zabójstwo św. Stanisława w dole oraz wskrzeszenie Piotrowina w części środkowej

${ }^{14}$ Tamże.

${ }^{15}$ Archiwum Urzędu Parafialnego w Krasnem, Protokót Czynności Urzędowych Parafii w Krasnem 1897-1937, dz. cyt.

${ }^{16}$ Por. tamże.

${ }^{17}$ „Krasne 1936 4xg 28.20 5xrep. 35” ( Wykaz robót witrażowych od 1929 roku, dz. cyt.).

${ }^{18} \mathrm{Na}$ trzecim oknie od południa napis: Zakład witrażów S. G. Żeleński Kraków 1936 - „Ofiara Walentego Lecha". W północnej ścianie, też w nawie, są cztery okna witrażowe, a na drugim od chóru napis: „Ofiara Ludwika i Franciszki Rudnickich”. Na innym „ofiara kobiet z różańca świętego”.

${ }^{19}$ Archiwum Urzędu Parafialnego w Krasnem, Protokót Czynności Urzędowych Parafii w Krasnem 1937-1947, rkps, brak numeracji stron.

${ }^{20}$ Por. Wykaz robót witrażowych od 1929 roku, dz. cyt. 
witraża. Przedstawienie to zajmuje największe pole wyznaczone ramą bordiury i dominuje w całości kompozycji. Postać biskupa, ukazana w bogatych szatach pontyfikalnych, wspiera się na pastorale i pochylając się nieco, wyciąga rękę nad spowitym w biały całun Piotrowinem, który odsuwa kamienną płytę i wychodzi z czeluści grobu. Scena rozgrywa się na tle pejzażu z panoramą starego Krakowa w głębi i zarysem gór na horyzoncie. Przedstawienie charakteryzuje godna uwagi wirtuozeria rysunku. Żywa, zmienna, zróżnicowana kreska oddaje bogactwo szczegółów stroju i elementów pejzażu. Krawędzie podziału szyb na pierwszym planie, w partii postaci przebiegają zgodnie z liniami zasadniczych konturów, ujmując nieregularną linią duże płaszczyzny przedstawienia. Kompozycja poszczególnych partii zamkniętych linią okonturowania została opracowana malarsko i z dużą biegłością techniczną. Zróżnicowany światłocień wprowadza przestrzeń i głębię, a delikatne podmalówki wydobywają szczegóły twarzy, ubioru czy też pejzażowego tła, ukazanego z zastosowaniem perspektywy powietrznej. W partii tła linie podziału poszczególnych tafli szkła tworzą kratownicę niezależną od zarysowującego się tam pejzażu, podkreślając podział na poszczególne plany. Kolorystyka sceny została oparta na zestawieniu w centralnej części przedstawienia barw dopełniających - czerwieni i zieleni. Wzbogaca ją płaszczyzna błękitu nieba w tle i biel całunu na pierwszym planie. Dwie pozostałe sceny zostały także oparte na dominacji barw dopełniających - żółcieni i filetów. W przedstawieniu zabójstwa św. Stanisława szczegóły wnętrza i drobne detale (nawet bardzo drobne, jak: ornamenty haftu czy żyłkowanie marmuru) zostały wydobyte przede wszystkim za pomocą barwnych podmalówek. O ile scena wskrzeszenia Piotrowina wywodzi się od schematu znanego jeszcze z czasów renesansu, o tyle przedstawienie zabójstwa świętego zawiera pewne elementy nietypowe i nawiązuje do nieco odmiennych wzorców ikonograficznych. Zazwyczaj męczeństwo biskupa krakowskiego przedstawiane jest podczas mszy świętej, której celebransem jest on sam, w momencie Podniesienia; autor kraśnieńskiego witraża ukazał świętego, którego mordercy zaskoczyli podczas modlitwy, klęczącego przed krucyfiksem stojącym na ołtarzu, jak przedstawiano często zabójstwo św. Tomasza Becketa. Motyw samej modlitwy przed ołtarzem występuje też raczej nie w ikonografii św. Stanisława, ale w przedstawieniach innych świętych, szczególnie w okresie potrydenckim, chociażby w obrazach św. Alojzego Gonzagi. Świadków zdarzenia oraz postać króla o wąsatej, srogiej twarzy, rzucającego się z mieczem na biskupa artysta odział w szaty, którym starał się nadać historyczną formę, bliższą jednak ubiorom renesansowym niż średniowiecznym.

Wymieniani w archiwum parafialnym ,,prof. Ekielski” i ,pan Tuch” byli założycielami i właścicielami nowo założonego w 1902 roku zakładu wyrobu witraży, działającego pod nazwą „Krakowski Zakład Witrażów, Oszkleń Artystycznych 
i Mozaiki Szklanej”21. Władysław Ekielski (1855-1927) był znanym krakowskim architektem, a w czasie, gdy wykonywano kraśnieńskie witraże pracował także jako wykładowca w Miejskiej Szkole Przemysłu Artystycznego w Krakowie. Jego wspólnik Antoni Tuch, który osobiście doglądał osadzenia okien witrażowych w Krasnem, przybył z Wiednia i był malarzem znanym przede wszystkim $\mathrm{z}$ realizacji z zakresu malarstwa monumentalnego, często wykonywanych według projektów innych twórców ${ }^{22}$. Ze Stefanem Matejką współpracował przy realizacji polichromii w kościele Mariackim. Ekielski od 1895 roku wykonywał prace restauracyjne w prezbiterium kościoła Franciszkanów w Krakowie. Tam też w 1897 roku Stefan Matejko wraz z Piotrem Nizińskim malował polichromię kaplicy Matki Boskiej Bolesnej. Może to bliższa znajomość zawarta podczas prac w krakowskich kościołach zaowocowała później propozycją współpracy złożoną Matejce przez zakład Ekielskiego i Tucha.

Stefan Matejko (1871-1933) był synem starszego brata Jana Matejki, studiował w krakowskiej Szkole Sztuk Pięknych pod kierunkiem między innymi swojego sławnego stryja, a następnie dzięki uzyskanemu stypendium doskonalił swe umiejętności w Monachium ${ }^{23}$. Po powrocie do Krakowa dał się poznać jako wykonawca polichromii kościelnych, ale także próbował swoich sił w innych dziedzinach malarstwa. Do dorobku Stefana Matejki należy zaliczyć dekoracje naczyń porcelanowych wykonywane dla fabryki fajansów „J. Niedźwiecki i Spółka” (1900-1910 $)^{24}$ oraz obrazy sztalugowe o tematyce popularniej i poszukiwanej na rynku dzieł sztuki w owym czasie. Były to ponętne akty kobiece („Rusałki”, „Nimfy”, „Świetliki”), malownicze pejzaże wiejskie („Świniopas”) oraz portrety ${ }^{25}$.

${ }^{21}$ Por. A. Laskowski, Działalność krakowskiego zaktadu witrażów Wt. Ekielskiego i A. Tucha, [w:] Dziedzictwo polskiej sztuki witrażowej, red. K. Pawłowska, J. Budyn-Kamykowska, Kraków 2000, s. 132-149; D. Czapczyńska-Kleszczyńska, Krakowski Zakład Witrażów, Oszkleń Artystycznych i Mozaiki Szklanej „S. G. Żeleński”, [w:] tamże, s. 150-161. Autorka wśród realizacji zakładu Ekielskiego i Tucha wymienia witraże w Krasnem.

${ }^{22}$ Już po napisaniu tego artykułu ukazał się tekst przybliżający tę postać: A. Laskowski, Antoni Tuch. Przyczynek do biografii, „Rocznik Krakowski” LXXIX (2013), s. 67-92 (za przypomnienie o tym tekście autorka dziękuje p. Recenzentowi).

${ }^{23}$ Por. R. Łoboda, $W$ cieniu wielkich mistrzów. O witrażach Stefana Matejki, ,, Sztuka Sakralna” $2002 \mathrm{nr}$ 2, s. 40-41; Artyści ze szkoły Jana Matejki: Wystawa Jubileuszowa w 80. rocznicę początków i w 20. rocznicę restytucji Muzeum Śląskiego w Katowicach, luty - kwiecień 2004 [katalog wystawy], teksty wprowadzające K. Jarmuł, Katowice 2004, s. 126-127; N. Cieślak, Witraże Stefana Witolda Matejki na tle odrodzenia malarstwa monumentalnego na przetomie XIX i XX wieku, praca lic., promotor: dr hab. Jan Wiktor Sienkiewicz, prof. UMK (Archiwum UMK w Toruniu).

${ }^{24}$ Por. B. Kołodziejowa, Fabryka fajansów „J. Niedźwiecki i Ska” w Dębnikach pod Krakowem (1900-1910), „Rocznik Muzeum Mazowieckiego w Płocku” z. 4, Płock 1973.

${ }^{25}$ Prace te przewijają się obecnie w ofertach różnych domów aukcyjnych. 
Współpraca z Ekielskim i Tuchem zainicjowała jego twórczość w dziedzinie witrażu, która z perspektywy czasu okazała się najcenniejsza w dorobku artysty.

W 1904 roku wspólnikiem Ekielskiego i Tucha w ich zakładzie witraży został Stanisław Gabriel Żeleński, który wraz z żoną Izabelą w 1907 roku wykupił udziały założycieli firmy, stając się jej jedynym właścicielem ${ }^{26}$. Żeleński kontynuował współpracę ze Stefanem Matejką, który był kierownikiem działu figuralnego zakładu, po zmianie właściciela działającego pod szyldem „Krakowski Zakład Witrażów S.G. Żeleński”. W rozwijającej się prężnie pod nowym kierownictwem firmie Stefan Matejko zaprojektował wiele witraży, szczególnie w kościołach Małopolski. W 1914 roku rozstał się z Żeleńskimi i próbował założyć konkurencyjną firmę. Jednak zamiary ambitnego artysty spełzły na niczym, a jego warsztat został wykupiony przez Izę Żeleńską, prowadzącą z powodzeniem zakład po śmierci męża.

Należy zauważyć, że w porównaniu z innymi dziełami Stefana Matejki, jak między innymi Wskrzeszenie Piotrowina z kościoła Miłosierdzia Bożego w Krakowie z 1908 roku (il. 3), św. Stanisław z Krasnego ukazany jest w sposób bardziej swobodny i dynamiczny, z większym rozmachem niż nieco sztywna sylwetka biskupa w przedstawieniu krakowskim. Niespokojne, wijące się linie całunu Piotrowina z Krasnego niczym nie przypominają spokojnie i naturalnie układających się fałdów jego koszuli na witrażu krakowskim. Również sposób ukazania pejzażu w tle jest odmienny. Rezygnacja z okonturowania poszczególnych elementów pejzażu w Krasnem nadała kompozycji większej przestrzenności niż w przedstawieniu krakowskim, czy na przykład w witrażach z kościoła misjonarzy w Tarnowie, gdzie zastosowano, jak często u Matejki, dekoracyjne ornamentalne tło dla przedstawień figuralnych. Odmienność kompozycji w Krasnem od innych realizacji typowych dla stylu tego artysty można próbować tłumaczyć tym, że Matejko w 1903 roku, tworząc dla tamtejszego kościoła, dopiero zaczynał karierę projektanta witraży. Dlatego zapewne wolał namalować pejzaż, niż układać go z kolorowych nieregularnych szybek. Różnice w sposobie opracowania draperii można też thumaczyć ewolucją indywidualnego stylu artysty. Mniej więcej w tym samym czasie firma Ekielskiego i Tucha zrealizowała bardziej prestiżowe zamówienie do kościoła św. Józefa na Staromieściu w Rzeszowie, ale stylistyka rzeszowskich przedstawień wyraźnie odbiega od formy witrażu w Krasnem. Można przypuszczać, że projekty przeszkleń do okazałej miejskiej świątyni wykonał artysta o większym doświadczeniu w tej dziedzinie.

Nieco więcej światła na kształtowanie się stylu malarstwa witrażowego Stefana Matejki rzuca analiza kartonów do innych jego witraży ze św. Stanisławem,

\footnotetext{
${ }^{26}$ Por. D. Czapczyńska-Kleszczyńska, Krakowski Zakład Witrażów, Oszkleń Artystycznych..., dz. cyt.
} 
przechowywanych w Muzeum Narodowym w Krakowie ${ }^{27}$. Matejko - artysta o tradycyjnym wykształceniu akademickim, stopniowo musiał uczyć się transponowania światłocieniowych iluzjonistycznych efektów malarskich na język witrażu uwzględniający wyrazistą jednolitą linię konturu. W jednym z kartonów artysta początkowo przewidywał delikatnie malarsko zarysowaną panoramę miasta, namalowaną na jednej dość dużej tafli szkła. W krakowskiej realizacji ten detal nie został uwzględniony, a w tle postaci występują drobne nieregularne szybki; ich wprowadzenie przyczyniło się do większej zwartości i jednolitości kompozycji.

Warto też zwrócić uwagę, że jeżeli rzeczywiście kraśnieński witraż, jak podaje Żeleński, został zaprojektowany przez Stefana Matejkę, to jest to najwcześniejsze dzieło witrażownicze tego artysty, o kilka lat wyprzedzające jego inne znane realizacje $w$ tej dziedzinie.

Przeszkleniu z przedstawieniem św. Stanisława w południowej ścianie prezbiterium kościoła w Krasnem odpowiada naprzeciw, od strony północnej, malowidło ukazujące nie św. Wojciecha, którego zazwyczaj przedstawiano w zestawieniu z biskupem Szczepanowskim, ale innego patrona Polski - Andrzeja Bobolę, jezuitę zamordowanego przez Kozaków w XVII wieku (il. 4). To nietypowe odejście od konwencji łączy się z ważnymi wydarzeniami w życiu Kościoła w Polsce i pozwala datować malowidło, o którym nie znaleziono dotychczas żadnej wzmianki w zachowanych archiwaliach.

W 1938 roku po uroczystej kanonizacji sprowadzono z Rzymu ciało św. Andrzeja, które po długiej tułaczce udało się wywieźć z ogarniętej rewolucyjnym zamętem Rosji ${ }^{28}$. Wydarzeniu temu towarzyszyły wielkie uroczystości w całym kraju. Trumnę z ciałem świętego witano w miastach, miasteczkach i wsiach na całej trasie przejazdu wiozącego ją pociągu. Zapewne pod wpływem tych wydarzeń w Krasnem zdecydowano się zastąpić zwyczajowe przedstawienie św. Wojciecha malowidłem ukazującym św. Andrzeja Bobolę. Obraz we wnęce, powtarzającej zarys zamurowanego okna, podzielono na trzy części dekoracyjnym obramieniem, identycznym jak w witrażu św. Stanisława. W największej - środkowej ukazano św. Andrzeja w całopostaciowym ujęciu frontalnym, gdy wędruje drogą, wiodącą wśród łąk i jezior. Święty ubrany jest w jezuicką sutannę z krzyżem na piersi, okrytą rozwianym na wietrze płaszczem. Jedną dłoń zaciska na kiju wędrowca, drugą - unosi w górę, wskazując na niebo. W tle widać zarys wiejskiej chaty i wzgórza na horyzoncie. Scena poniżej ukazuje szeroki

${ }^{27}$ Zdjęcia witrażu krakowskiego oraz kartonów z wizerunkiem św. Stanisława zostały udostępnione przez p. Danutę Czapczyńską-Kleszczyńską.

${ }^{28}$ Por. Z. Kotkowski, Św. Andrzej Bobola: męczennik-wielki patron polski, Warszawa 1962, s. 41-48. 
gościniec, po którym w równym szeregu posuwa się grupa Kozaków na koniach. W całości widoczny jest tylko skrajny jeździec, który prowadzi związanego Andrzeja Bobolę. Jedną rękę unosi w górę z rozmachem, bijąc świętego nahajem, drugą ściąga wodze konia. Jego sylwetka przesłania postaci pozostałych trzech czy czterech jeźdźców. Droga prowadzi wśród łąk, a w głębi widać dwie grupy gęsto rosnących drzew.

W polu wykreślonym przez ozdobne obramienie najwyżej, ponad opisanymi scenami ukazana została kapliczka wzniesiona na miejscu zamordowania męczennika w Janowie Poleskim, a w tle widać fragment tamtejszej cerkwi Pokrowskiej. Obie budowle otaczają kłęby chmur, a z góry z lewej strony pada snop światła, ogarniający zarówno kapliczkę, jak i cerkiew. Całość została utrzymana w tonacji szaro-brązowo-zielonkawej, dopełnionej dużymi płaszczyznami niebieskiego nieba. Autorowi malowidła wyraźnie zależało na stworzeniu iluzji witrażu. Zaznaczył grube ankry w oknach, kratownicę podziałów szyb i wyraziste, jakby witrażowe okonturowania poszczególnych elementów przedstawień. O ile w witrażu ze św. Stanisławem występuje tylko ogólny związek z powszechnie stosowanymi schematami kompozycyjnymi, o tyle malowidło poświęcone św. Andrzejowi Boboli stanowi dokładną transpozycję kilku przedstawień, związanych z ikonografią tego świętego. Główna scena jest wzorowana na popularnym, wielekroć kopiowanym obrazie świętego pędzla Stefana Bakałowicza (1857-1947), powstałym w Rzymie w latach 1923-1938 i przewiezionym po kanonizacji świętego do poznańskiego kościoła Jezuitów (il. 5) ${ }^{29}$. Przedstawienie św. Andrzeja, prowadzonego przez Kozaków, do złudzenia przypomina jedną ze scen tryptyku pędzla Pawła Poraj Paradowskiego, który reprodukowano w „Ilustrowanym Kurierze Codziennym" w 1939 roku $^{30}$. Natomiast widok kapliczki w Janowie Poleskim skopiowano z najdrobniejszymi szczegółami ze zdjęcia zamieszczonego w książce ks. Jana Urbana Święty Andrzej Bobola, wydanej w Warszawie w 1938 roku (il. 6,7) ${ }^{31}$. Nazwisko autora kompozycji ukazującej św. Andrzeja w kraśnieńskim kościele nie jest znane. Był zręcznym kopistą, może pracował w zakładzie Żeleńskich i potrafił przetransponować dostarczone mu wzory na język witrażu. Być może na zamówienie proboszcza stworzył karton witrażu, który miano zrealizować później, ale ostatecznie zdecydowano się na pozostawienie

${ }^{29}$ Por. J. Derwojec, Stefan Bakałowicz, [w:] Stownik artystów polskich, Ossolineum 1991, s. 72-73. Obraz był reprodukowany na okładce miesięcznika: „Missye Katolickie. Czasopismo miesięczne ilustrowane" 58 (1939) nr 1.

${ }^{30}$ Narodowe Archiwum Cyfrowe, Koncern Ilustrowany Kurier Codzienny - Archiwum Ilustracji, Sygn. 1-K-4552.

${ }^{31}$ Podpis pod zdjęciem głosi: Kolumna na miejscu męczeństwa św. Andrzeja Boboli w Janowie Poleskim (s. 25). 
zamurowanego okna i przeniesienie projektu witraża $\mathrm{w}$ formie malowidła przy okazji prac malarskich wykonywanych w nawie kościoła.

W ostatnich latach nastąpiła intensyfikacja badań nad polskim malarstwem witrażowym przełomu XIX i XX wieku związana przede wszystkim z prężną realizacją projektu „Korpus witraży z lat 1800-1945 w kościołach rzymskokatolickich metropolii krakowskiej i przemyskiej”. Należy żywić nadzieję, że w trakcie dalszych prac może zostanie odnaleziona szersza dokumentacja, pozwalająca na uściślenie ustaleń kwerendy źródłowej oraz weryfikację analiz zaprezentowanych w niniejszym artykule. 
Il. 1. Kościół Wniebowzięcia Najświętszej Marii Panny i św. Małgorzaty w Krasnem (dawniej parafialny), 1742-1752, widok od wschodu. Fot. Archiwum Parafialne w Krasnem.

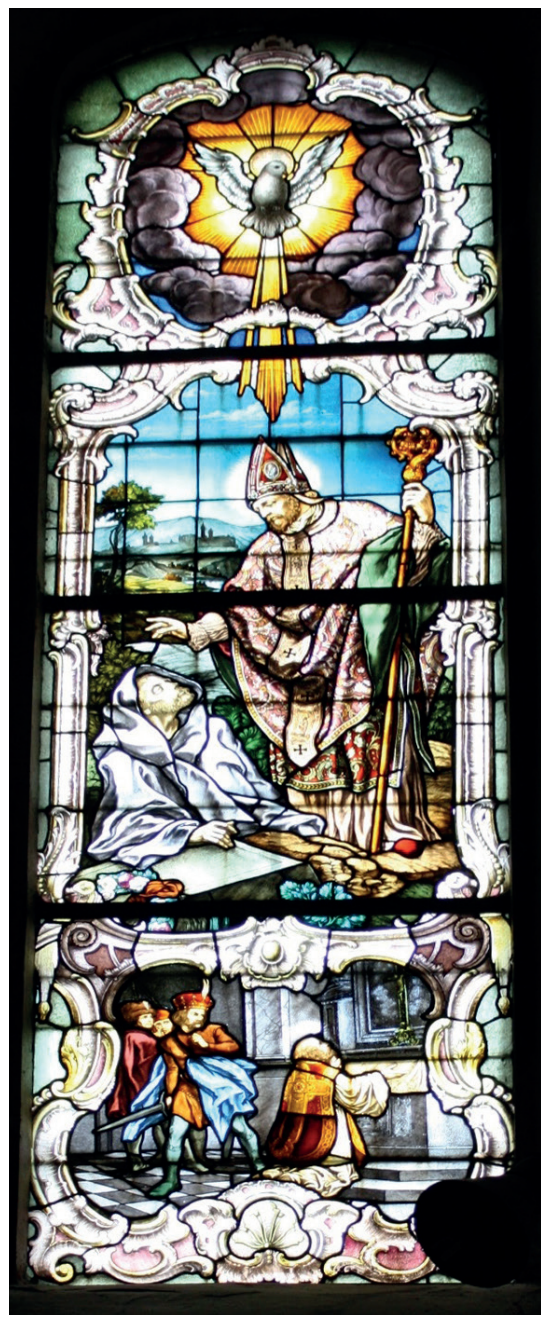

Il. 2. Św. Stanisław biskup, witraż w oknie południowym prezbiterium w kościele pw. Wniebowzięcia Najświętszej Marii Panny i św. Małgorzaty w Krasnem (dawniej parafialny), 1903, proj. S. Matejko, wyk. Krakowski Zakład Witrażów, Oszkleń Artystycznych i Mozaiki Szklanej. Fot. Archiwum Parafialne w Krasnem.
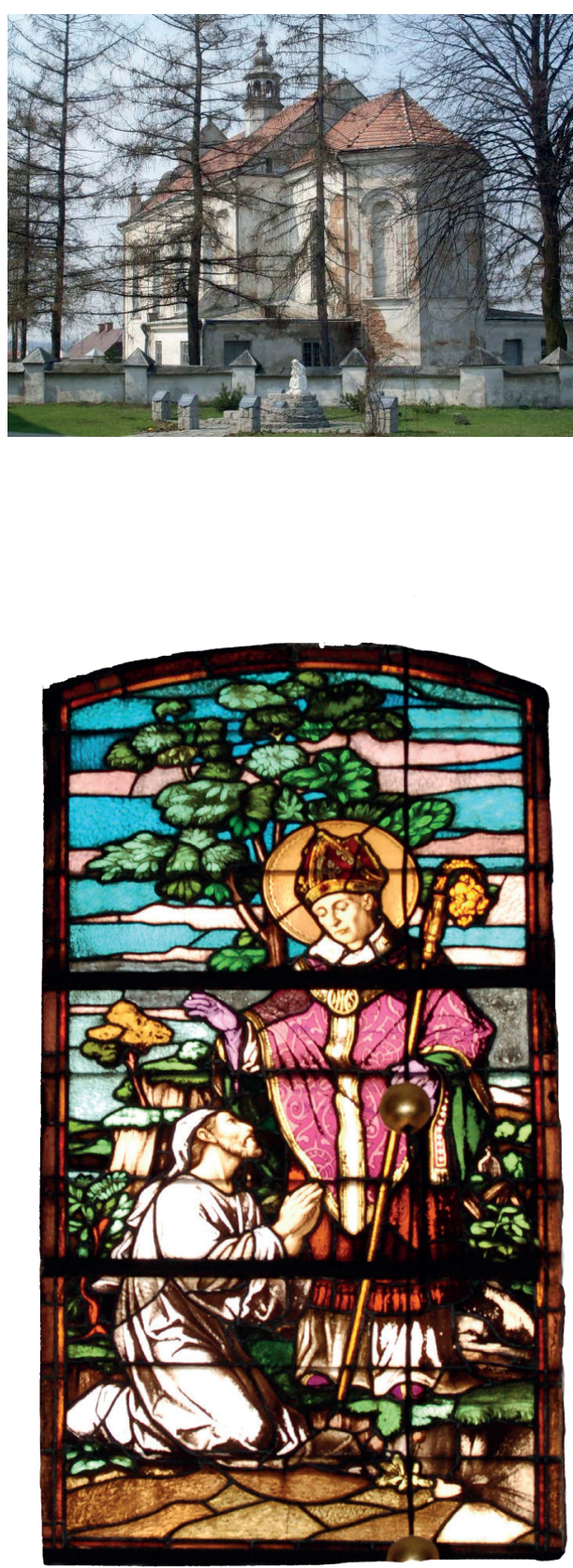

I1. 3. Wskrzeszenie Piotrowina, witraż w kościele Miłosierdzia Bożego w Krakowie, 1908, proj. Stefan Matejko, wyk. Krakowski Zakład Witrażów S.G. Żeleński. Fot. Danuta Czapczyńska-Kleszczyńska. 


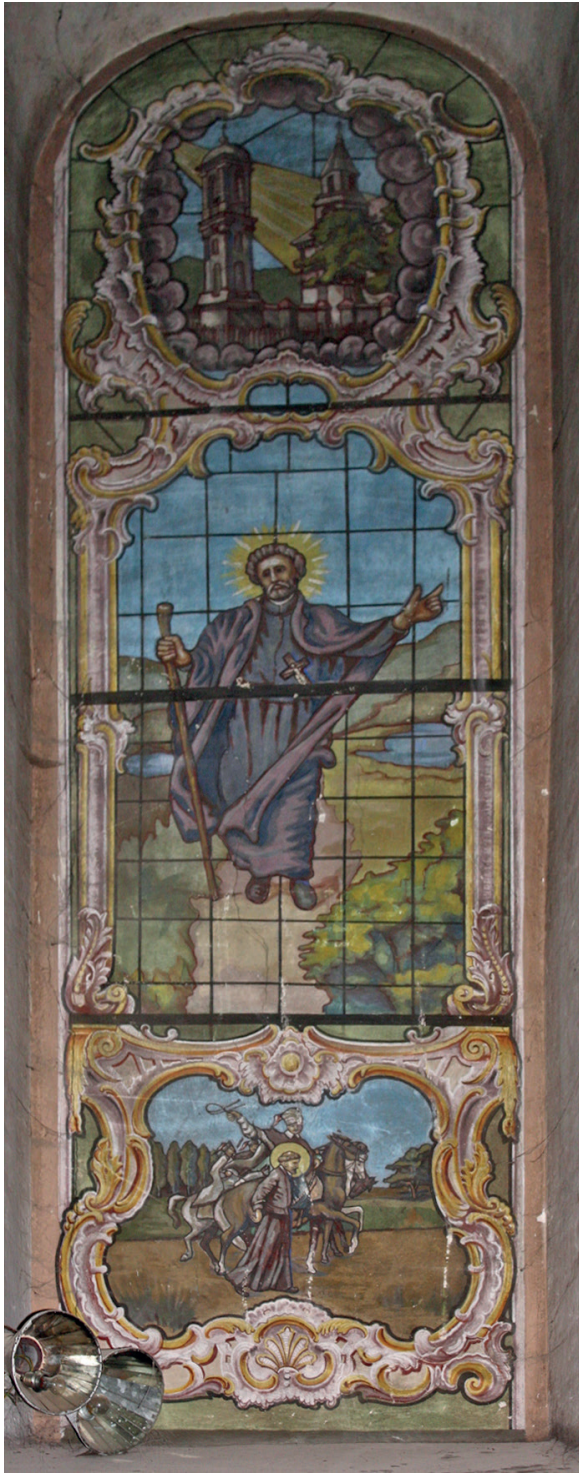

Il. 4. Św. Andrzej Bobola, malowidło ścienne we wnęce zamurowanego okna południowego prezbiterium kościoła Wniebowzięcia Najświętszej Marii Panny i św. Małgorzaty w Krasnem (dawniej parafialny), po 1938. Fot. Archiwum Parafialne w Krasnem.

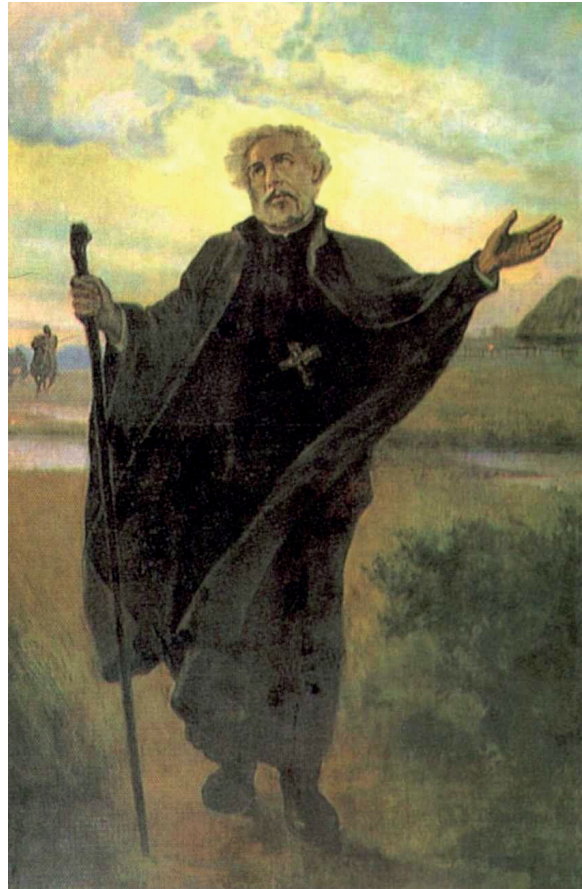

Il. 5. Stefan Bakałowicz, Św. Andrzej Bobola, olej, płótno, kościół pw. Najświętszego Serca Pana Jezusa i Matki Bożej Pocieszenia w Poznaniu. Fot. wikimedia. org/wikipedia/commons/7/73/Bobola.jpg 


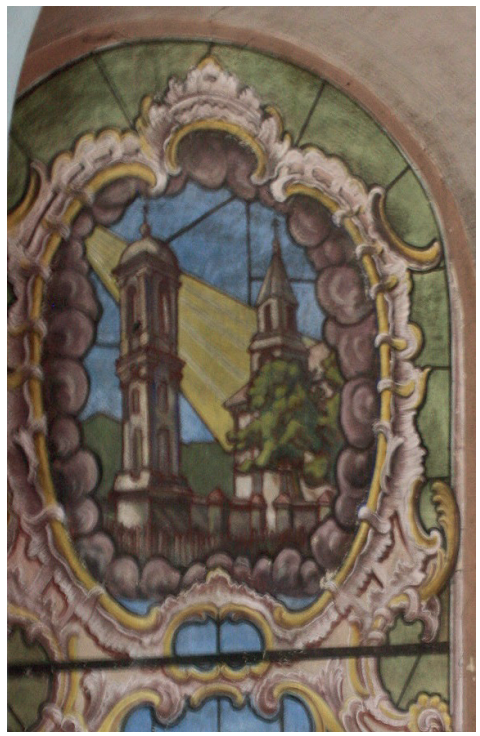

Il. 6. Kapliczka na miejscu śmierci św. Andrzeja Boboli w Janowie Poleskim, fragment malowidła ściennego we wnęce zamurowanego okna południowego prezbiterium kościoła pw. Wniebowzięcia Najświętszej Marii Panny i św. Małgorzaty w Krasnem (dawniej parafialny), po 1938. Fot. Archiwum Parafialne w Krasnem.

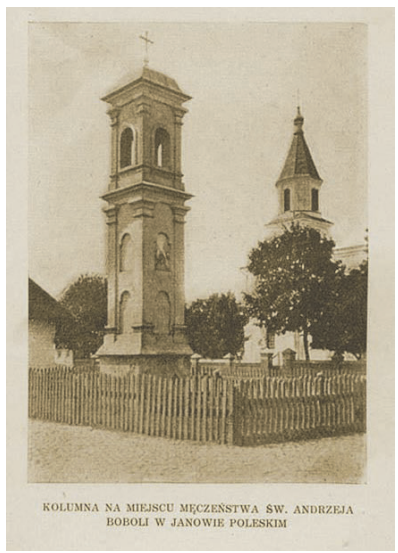

Il. 7. Kapliczka na miejscu śmierci św. Andrzeja Boboli w Janowie Poleskim, fotografia reprodukowana w: ks. Jan Urban, Święty Andrzej Bobola, Warszawa 1938, s. 25. 


\section{Abstrakt \\ Święci z kościoła w Krasnem koło Rzeszowa. Przyczynek do badań nad twórczością Stefana Matejki}

W podrzeszowskiej parafii Krasne znajduje się niewielki kościół, wzniesiony w latach 1742-1752 w stylu prowincjonalnego późnego baroku. W 1903 roku w budowli tej zostały wstawione witraże przez firmę Krakowski Zakład Witrażów Władysława Ekielskiego i Antoniego Tucha. Wśród zrealizowanych wtedy przeszkleń był witraż wykonany według projektu Stefana Matejki. Jest to pierwsze znane dzieło witrażownicze tego artysty, o kilka lat wyprzedzające jego inne znane realizacje w tej dziedzinie. W artykule dokonano charakterystyki witrażu z Krasnego w odniesieniu do późniejszej twórczości artysty i w porównaniu z analogicznymi realizacjami na terenie obecnego Podkarpacia. W kościele w Krasnem znajduje się także swoisty pseudowitraż stanowiący dopełnienie dzieła Matejki - fresk naśladujący witraż ukazujący św. Andrzeja Bobolę. Artykuł podaje źródła ikonograficzne przedstawienia oraz opisuje szczególny kontekst jego powstania.

Słowa kluczowe: Stefan Matejko, Krasne koło Rzeszowa, św. Stanisław Biskup, św. Andrzej Bobola

\section{Abstract \\ The saints of the church in Krasne near Rzeszow. Contribution to the study of Stefan Matejko creativity}

In the parish of Krasne near Rzeszów there is a small church erected in the years 1742-1752 in the style of the provincial late Baroque. In 1903 in the church, stained glass windows were installed by the Cracow Stained Glass Studio of Władysław Ekielski and Antoni Tuch. Among the stained glass windows made then was one designed by Stefan Matejko. This is the first known stained glass work of that artist, preceding by a few years his other well-known projects in this field. The paper presents the characteristics of the stained glass in Krasne in relation to the later works of the artist and in comparison with the corresponding realizations in the region of the present Podkarpacie. The church in Krasne also has a kind of pseudo-window which complements the work by Matejko: a mural that imitates the stained glass showing St. Andrew Bobola. The paper presents the iconographic sources of that work and the particular context of its creation.

Keywords: Stefan Matejko, Krasne near Rzeszów, St. Stanislaus of Cracow, St. Andrew Bobola 


\section{Bibliografia}

Artyści ze szkoły Jana Matejki: Wystawa Jubileuszowa w 80. rocznicę początków i w 20. rocznice restytucji Muzeum Ślaskiego w Katowicach, luty - kwiecień 2004 [katalog wystawy], teksty wprowadzające K. Jarmul, Katowice 2004.

Cieślak N., Witraże Stefana Witolda Matejki na tle odrodzenia malarstwa monumentalnego na przełomie XIX i XX wieku, praca lic., promotor: dr hab. Jan Wiktor Sienkiewicz, prof. UMK (Archiwum UMK w Toruniu) Torun 2010.

Czapczyńska-Kleszczyńska D., Krakowski Zakład Witrażów, Oszkleń Artystycznych i Mozaiki Szklanej ,,S. G. Żeleński”, [w:] Dziedzictwo polskiej sztuki witrażowej, red. K. Pawłowska, J. Budyn-Kamykowska, Kraków 2000, s. 150-161.

Czapczyńska-Kleszczyńska D., Zapomniani twórcy, stan badań nad polskim witrażownictwem (druga połowa XIX wieku - rok 1945), „Sacrum et Decorum” 1 (2008), s. 94-103.

Kołodziejowa B., Fabryka fajansów „,J. Niedźwiecki i Ska” w Dębnikach pod Krakowem (1900-1910), „Rocznik Muzeum Mazowieckiego w Płocku” 1973, z. 4.

Kotkowski Z., Św. Andrzej Bobola: męczennik-wielki patron Polski, Warszawa 1962.

Laskowski A., Działalność krakowskiego zakładu witrażów Wt. Ekielskiego i A. Tucha, [w:] Dziedzictwo polskiej sztuki witrażowej, red. K. Pawłowska, J. Budyn-Kamykowska, Kraków 2000, s. 132-149.

Laskowski A., Über die Arbeiten der Wiener Glasmalereiwerkstatt Carl Geyling's Erben in Galizien, „Jahrbuch des Wissenschaftlichen Zentrums der Polnischen Akademie der wissenschaften in Wien" Bd. 2 (2009), s. 12-142.

Łoboda R., W cieniu wielkich mistrzów. O witrażach Stefana Matejki, „Sztuka Sakralna” 2002 nr 2, s. $40-41$.

Oršulová J., Sklomaliarska Firma Karola Geylinga, „Zborník Slovenského Národného Múzea” 92 (1998), s. 5-24. 
